University of Nebraska - Lincoln

DigitalCommons@University of Nebraska - Lincoln

\title{
Predicting the Counterproductive Employee in a Child-to-Adult Prospective Study
}

\author{
Brent W. Roberts \\ University of Illinois, Urbana-Champaign, bwrobrts@illinois.edu \\ Peter D. Harms \\ University of Nebraska - Lincoln, pharms@gmail.com \\ Avshalom Caspi \\ King's College, London, \& University of Wisconsin-Madison \\ Terri E. Moffitt \\ King's College, London, \& University of Wisconsin-Madison
}

Follow this and additional works at: https://digitalcommons.unl.edu/managementfacpub

Part of the Management Sciences and Quantitative Methods Commons

\footnotetext{
Roberts, Brent W.; Harms, Peter D.; Caspi, Avshalom; and Moffitt, Terri E., "Predicting the Counterproductive Employee in a Child-to-Adult Prospective Study" (2007). Management Department Faculty Publications. 45.

https://digitalcommons.unl.edu/managementfacpub/45
}

This Article is brought to you for free and open access by the Management Department at DigitalCommons@University of Nebraska - Lincoln. It has been accepted for inclusion in Management Department Faculty Publications by an authorized administrator of DigitalCommons@University of Nebraska - Lincoln. 
Published in Journal of Applied Psychology 92:5 (September 2007), pp. 1427-1436; doi: 10.1037/0021-9010.92.5.1427 Copyright ( 2007 American Psychological Association. Used by permission. "This article may not exactly replicate the final version published in the APA journal. It is not the copy of record." http://www.apa.org/journals/jap/

Preparation of this article was supported by National Institute of Aging Grant AG19414, National Institute of Mental Health Grants MH49414 and MH45070, and United Kingdom Medical Research Council Grant G0100527. The Dunedin Multidisciplinary Health and Development Research Unit is supported by the Health Research Council of New Zealand. Our thanks go to the study participants and to unit director Richie Poulton for comments on an earlier version of this article.

Submitted April 4, 2006; revised January 10, 2007; accepted: January 12, 2007.

\title{
Predicting the Counterproductive Employee in a Child-to-Adult Prospective Study
}

\author{
Brent W. Roberts \& Peter D. Harms \\ Department of Psychology, University of Illinois, Urbana-Champaign
}

\author{
Avshalom Caspi \& Terri E. Moffitt \\ Institute of Psychiatry, King's College London, London, England, and Department of Psychology, University of Wisconsin-Madison
}

Corresponding author - Brent W. Roberts, Department of Psychology, University of Illinois, Urbana-Champaign, 603 East Daniel Street, Champaign, IL 61820; email broberts@cyrus.psych.uiuc.edu.

\begin{abstract}
The present research tested the relations between a battery of background factors and counterproductive work behaviors in a 23-year longitudinal study of young adults $(N=930)$. Background information, such as diagnosed adolescent conduct disorder, criminal conviction records, intelligence, and personality traits, was assessed before participants entered the labor force. These background factors were combined with work conditions at age 26 to predict counterproductive work behaviors at age 26 . The results showed that people diagnosed with childhood conduct disorder were more prone to commit counterproductive work behaviors in young adulthood and that these associations were partially mediated by personality traits measured at age 18. Contrary to expectations, criminal convictions that occurred prior to entering the workforce were unrelated to counterproductive work behaviors. Job conditions and personality traits had independent effects on counterproductive work behaviors, above and beyond background factors.
\end{abstract}

Keywords: personality traits, counterproductive work behaviors, longitudinal, predictive validity

According to Ones (2002), "counterproductive work behaviors [CWBs] include but are not limited to theft, white collar crime, absenteeism, tardiness, drug and alcohol abuse, disciplinary problems, accidents, sabotage, sexual harassment, and violence" (p. 1). Clearly, employers would prefer to not hire individuals with the propensity to engage in CWBs. One of the primary techniques used to avoid hiring counterproductive employees is to screen applicants using past behaviors (criminal background checks) and psychological tests, such as integrity and personality tests (Ones, Viswesvaran, \& Schmidt, 1993). The assumption behind screening applicants is that people's history, both in terms of what they have done and what they typically do, will predict how they behave on the job. This assumption is derived in part from the perspective that there will be some continuity in behavior and personality, such that past behavior will predict future behavior and personality traits will be stable over long periods of time.

Ideally, the validity of personality tests and background checks would be established using a prospective longitudinal study in which information on employees is gathered, using valid techniques, as their lives unfold. For many reasons, this ideal study design is elusive, as most validity research is carried out in organizations that ask job applicants to provide background information. Such applicants provide either selfreports of relevant variables or retrospective accounts of their activities using biodata collection techniques. Asking people directly whether they have committed a crime or stolen from their previous employer may not be the ideal technique, as people can lie in the attempt to gain employment. Even when a person attempts to be honest, retrospective reports of past delinquent behaviors can be quite unreliable (Henry, Moffitt, Caspi, Langley, \& Silva, 1994). Of course, background checks only yield relevant information if the person has been arrested, prosecuted, and convicted; has poor credit; or has filed for bankruptcy. Crime records are known to underdetect crimes committed, as most offenses are never cleared or successfully prosecuted. In reality, most employers must rely on the honesty of applicants or their references for gathering historical facts about their behavior.

In the present study, we present an alternative approach to understanding the relationship of background factors to CWBs. We took advantage of data gathered as part of the Dunedin Multidisciplinary Health and Development Study (Silva \& Stanton, 1996). The participants in the Dunedin study are a birth cohort of New Zealand residents who have been tracked from birth to age 26 with good retention. Approximately every 3 years, the participants were exhaustively interviewed by physicians and psychologists. Along the way, much relevant information was gathered that can be used to predict CWBs. For the present study, we used background information collected during childhood and adolescence to predict CWBs on the job at age 26.

This approach is different than the typical validation study in which a select group of job incumbents is surveyed and followed in a particular occupation or set of occupations (Lau, $\mathrm{Au}, \&$ Ho, 2003; Sackett \& DeVore, 2001). The typical validation study provides predictive validity information for constructs that can be assessed within a typical selection procedure 
on a particular sample of individuals. In contrast, the present study entailed an examination of the validity of a combination of constructs, some that are common in selection procedures, such as personality tests, and some that are not typically assessed in a selection process, such as childhood variables. This type of design can be used for several purposes, including testing whether the typical selection constructs can serve as proxies for background variables and seeing whether they are confounded by these constructs. The present study also focused on a cross-section of individuals across a large number of jobs. Therefore, the findings are more difficult to generalize to any particular occupation. However, akin to a generalizability study, the findings may then be generalizable to a larger number of occupations. In general, then, the present design provides complementary information on the long-term predictive validity of a number of factors used in selection procedures. The goal was to provide a more complete picture of how these factors might affect CWBs.

In terms of previous behaviors, the Dunedin study has long examined behavioral phenomena distinctly similar to CWBs, such as childhood and adolescent conduct disorder, as well as criminal activity that occurred during adolescence (Moffitt, Caspi, Rutter, \& Silva, 2001). From a behavioral perspective, there is a remarkable overlap between CWBs and the typical behaviors used to diagnose someone with conduct disorder. For example, both the counterproductive worker and the person diagnosed with conduct disorder are described as not conforming to social norms, breaking laws, lying, committing acts of violence such as physical fights and assaults, and disregarding the safety of others; see the Diagnostic and Statistical Manual of Mental Disorders (4th ed.; DSM-IV; American Psychiatric Association, 1994). Therefore, we hypothesized that adolescent behaviors indicative of conduct disorder would predict adult CWBs.

Criminal activities would appear to be highly relevant to counterproductive behaviors, as many of the actions considered to be counterproductive are also criminal. Given the relatively strong relationship between past behavior and present behavior (Meyer et al., 2001), one would assume that criminal activities and CWBs would be positively correlated. This is, of course, the justification for the widespread use of criminal background checks by employers, as businesses can be held liable for employees' actions, especially if they result in harm to other workers or clients (Connerley, Arvey, \& Bernardy, 2001). Surprisingly, though, there is little or no published research reporting the relationship between having a criminal background and engaging in subsequent counterproductive behaviors on the job. In the present study we examined both conduct disorder and criminal conviction assessed in adolescence as prospective predictors of CWBs in adulthood.

The Dunedin study has also assessed cognitive ability and personality prospectively. In the current study, we drew on IQ scores prospectively assessed during childhood using the Weschler tests of cognitive ability. The relationship between cognitive ability and CWBs is unclear, as few published studies have reported on the direct relationship. Cognitive ability tends to be relatively unrelated to similar constructs such as contextual performance (LePine \& Van Dyne, 2001), yet there is some evidence that it is negatively related to organizational deviance and facets of integrity, such as theft admissions (Duehr, Sackett, \& Ones, 2006; Dilchert, Ones, Davis, \& Rostow, 2007). Therefore our expectation was that childhood cognitive ability would be negatively related to CWBs.
Research to date supports the inference that personality tests are related to CWBs. Although different measures of personality and different systems of describing personality traits have been examined, most research has found that low agreeableness (high hostility) and low conscientiousness are key correlates of CWBs (Berry, Ones, \& Sackett, 2007; Colbert, Mount, Harter, Witt, \& Barrick, 2004; Lau et al., 2003; Lee, Ashton, \& Shin, 2005; Ones \& Viswesvaran, 2003; Sackett \& DeVore, 2001; Salgado, 2002). Some research has also found a substantial effect for a trait variously called low emotional stability, negative affectivity, or neuroticism that predicts CWBs such as substance abuse at work (Ones \& Viswesvaran, 2001). Potentially, the most relevant aspect of negative affectivity in relation to CWBs is hostility, a form of low agreeableness. Lee and Allen (2002) demonstrated that only the hostility aspect of negative affect showed significant relationships with a broad range of CWBs. Further, hostility remained one of the best predictors of CWBs even when a number of other background factors, such as age, education, and organizational characteristics, were taken into account. In the present study we examined these traits assessed in adolescence as prospective predictors of CWBs in adulthood.

To evaluate the role of personality in CWBs in young adulthood, we drew on self-reported personality assessments gathered at age 18 using the Multidimensional Personality Questionnaire (MPQ; Tellegen, 1982). The MPQ includes measures that tap the facets of Agreeableness, Conscientiousness, and Neuroticism related to CWBs. Specifically, these scales are found in the superordinate MPQ domains of Negative Emotionality and Constraint. Negative Emotionality in Tellegen's system includes aggressiveness, which is typically a marker of low Agreeableness in the Big Five framework. Negative emotionality also includes dimensions that tap the anxiety and alienation common to measures of Neuroticism. Constraint is a variant of Conscientiousness that emphasizes the impulse control and conventionality aspects of Conscientiousness over the typical orderliness and achievement components of Conscientiousness (Roberts, Chernyshenko, Stark, \& Goldberg, 2005). We also examined the relations between CWBs and the remaining two domains tapped by the MPQ, Agentic Positive Emotionality and Communal Positive Emotionality, with no a priori expectations for how these trait domains should relate to CWBs.

We drew on measures of CWBs administered when the sample was assessed at age 26 . At this age, the study members occupied a wide range of jobs from slaughterer to government officer. In predicting CWBs, we also included organizational and workplace variables assessed at age 26 that were developed in previous research on the Dunedin study (Roberts, Caspi, \& Moffitt, 2003). These variables include many factors that have been investigated in research on CWBs, such as job satisfaction (Robinson \& O'Leary-Kelly, 1998), occupational attainment, power, and autonomy (Hollinger \& Clark, 1983; Robinson \& O'Leary-Kelly, 1998).

The present design offers two advantages. First, most of the relevant variables were assessed well before the majority of the participants entered the labor market. Thus, we were able to test the prospective effect of background factors such as adolescent conduct disorder, criminal conviction, and adolescent personality on subsequent CWBs in work. Second, we included both psychological and contextual factors in the prediction of CWBs under the assumption that both personality 
traits and work conditions influence CWBs. On the basis of previous research, we made the following hypotheses:

- Hypothesis 1: Adolescent conduct disorder will be positively related to CWBs at age 26 .

- Hypothesis 2: Adolescent criminal convictions through age 18 will be positively related to CWBs at age 26 .

- Hypothesis 3: Cognitive ability assessed in childhood will be negatively related to CWBs at age 26 .

- Hypothesis 4: Personality traits from the domain of Conscientiousness-Constraint will be negatively related to CWBs at age 26.

- Hypothesis 5: Personality traits from the domain of Negative Emotionality (inclusive of aggression, which is also low Agreeableness) will be positively related to CWBs at age 26 .

- Hypothesis 6: Most variables representing desirable occupational conditions, such as satisfaction, occupational attainment, and autonomy, will be negatively related to CWBs at age 26 .

\section{Method}

\section{Participants}

Participants were members of the Dunedin study (see Silva \& Stanton, 1996), a longitudinal investigation of the health and behavior of a complete cohort of consecutive births born between April 1, 1972, and March 31, 1973, in Dunedin, New Zealand. When the children were traced for follow-up at 3 years of age, 1,037 children ( $91 \%$ of the eligible births, of whom $52 \%$ were boys) participated in the assessment and formed the base sample for the longitudinal study. With regard to social origins, the children's families are representative of the social class and ethnic distribution in the general population of New Zealand's South Island. With regard to ethnic distribution, the Dunedin study members are of predominantly European ancestry. Cross-national comparisons and replication analyses lend some confidence about generalizing findings from the Dunedin study to other Western nations (see Moffitt, Caspi, Rutter, \& Silva, 2001). Follow-ups of the sample have been carried out at ages $5,7,9,11,13,15,18,21$, and 26, when 980 $(96 \%)$ of the 1,019 study members still alive were assessed. The present sample $(N=930)$ included all individuals who indicated that they were employed currently or at some time during the year prior to the interview (i.e., not homemakers) and thus could report about a job experience in the past 12 months. Study members who were in prison on their interview date reported about their most recent job.

\section{Measures}

Predictors in this study were measured up to age 18, stopping at that age because up to age 18 most of the cohort members attended secondary school, lived at home with their parents, and did not work full-time. Thus, predictors assessed up to age 18 were used because it was very unlikely that the scores would have been affected by cohort members' experience of employment or by any CWBs committed in the jobs held by cohort members.
Adolescent conduct disorder. Conduct disorder was measured according to $D S M-I V$ criteria, which identify adolescents displaying a persistent pattern of behavior that violates the rights of others, including physical harm. A diagnosis of conduct disorder (using a 12-month reporting period for symptoms) was made when the research participants at each of four ages were assessed (ages 11, 13,15, and 18). A "lifetime" diagnosis was arrived at by establishing whether a study member received the diagnosis at one or more of the four ages (according to the $D S M-I V$, conduct disorder is not normally diagnosed after age 18). The internal consistency of the conduct disorder items averaged across multiple judges and rating occasions was .83 (Moffitt et al., 2001).

Adolescent criminal conviction. Computerized records of convictions at all courts in New Zealand and Australia for 932 study members were obtained by searching the central computer system of the New Zealand Police for matches by name and birth date. These records included convictions in Children's and Young Person's Court from age 13 to age 16 inclusive and convictions in adult Criminal Courts from age 17 until the 18th birthday. Traffic offenses and criminal offenses were handled by two separate law-enforcement agencies in New Zealand at that time, and as a result traffic offenses are not included in our criminal conviction measure, which covers mainly property crimes, drug crimes, and violence. Informed consent for the search was obtained during the age-18 interviews. Conviction data could not be obtained for study members who did not participate in the assessment, were deceased, did not give informed consent for the search, or lived outside New Zealand and Australia (the 22 study members who did not provide consent for the search did not differ from the whole cohort on self-reported or parent-reported delinquency at age 15). The number of court convictions ranged from 0 to $68 ; 25 \%$ of male participants and $12 \%$ of female participants had been convicted at least once.

Childhood cognitive ability. Intelligence was assessed using the Wechsler's Intelligence Scale for Children-Revised (Wechsler, 1974), administered at ages 7, 9, 11, and 13 years. The IQ scores for the four age periods were averaged to form an overall score $(M=107.7, S D=14.3$, range $=40-147)$.

Personality traits. As part of the age-18 assessment, participants completed a modified version (Form NZ) of the MPQ (Tellegen, 1982; see also Krueger, Caspi, \& Moffitt, 2000). The MPQ is a self-report personality instrument designed to assess a broad range of individual differences in affective and behavioral style and yields 10 primary scales (the Absorption scale was not included in the administration of the MPQ). These 10 primary scales can be organized under a three-factor structure (Negative Emotionality, Positive Emotionality, and Constraint).

Negative Emotionality is a combination of the Aggression, Alienation, and Stress Reaction scales. Individuals high on this dimension have a low general threshold for the experience of negative emotions such as fear, anxiety, hostility, and anger and tend to be involved in antagonistic relationships. Constraint is a combination of the Traditionalism, Harm Avoidance, and Self-Control scales. Individuals high on this factor tend to endorse social norms, act in a cautious and restrained manner, and avoid thrills. Positive Emotionality is a combination of the Social Closeness, Well-Being, Social Potency, and Achievement scales and reflects positive emotional responsiveness, interpersonal connectedness, and dominance. We 
scored these superfactors by summing the relevant subscales and used these as a supplement to the primary MPQ scales.

\section{Measures Assessed at Age 26}

Work conditions and attitudes. The participants' workplace environment was assessed with several variables. The first variable was occupational attainment, which is a composite of job prestige, job complexity, education level, pretax hourly wages, and whether participants got dirty on the job (reversed; $a=.75$; see Roberts, Caspi, \& Moffitt, 2003). The second variable was work autonomy, which was a composite of whether participants had a boss (reversed), whether their boss had a boss (reversed), whether they could set their own hours, and whether they were responsible for a budget $(\alpha=.63)$. The third workplace variable was resource power, which was a combination of items tapping whether the person had a say in hiring or firing people, whether they had a say in pay raises and pay cuts, whether they supervised others, and the number of people they supervised $(\alpha=.67)$. The final workplace factor, work satisfaction, was measured with self-report interview questions that tapped the Dunedin study members' satisfaction with work (Greenberger \& O'Neil, 1993). Sample items from the work satisfaction scale included "How satisfied are you in this job?" scored on a 3-point scale with response options ranging from not satisfied (0) to very satisfied (2), "Do you often think of quitting your job?" scored on a 2-point scale $(0$ = yes, $1=n o$ ), and "Is this the right job for you?" scored on a 2point scale $(1=$ yes, $0=n o)$. Items were $z$ scored before being combined into a scale. The five-item job satisfaction scale had an alpha reliability of .69 .

Counterproductive work behavior. Work experiences were assessed by interviewing Dunedin study members about their work as part of a life-history interview inquiring about their transition to adulthood. Counterproductive workplace behaviors were assessed with 11 interview questions concerning the frequency of the following behaviors over the previous year: number of times late to work, number of days absent under pretense, number of times using prohibited work materials, number of conflicts with boss, number of fights-arguments at work, number of times doing something at work that could get them fired, number of times they stole money from work, number of times they lied on their time sheet, number of times they stole things from work, number of times they damaged work property, and number of times they were drunk or on drugs at work. Rather than using direct frequencies, which have problematic psychometric properties for low-base-rate behaviors, we first categorized scores on each behavior for the presence (scored 1) or absence (scored 0 ) of the behavior. We then subjected these 11 items to an item response theory (IRT) analysis to determine the dimensionality of the index and to properly score the index.

Because the items were dichotomous and ranged in their endorsement frequency, we used IRT methods to determine the structure and score the overall index of CWBs. For most IRT models, it is assumed that a single underlying latent trait or ability is sufficient to account for examinee performance. To test the unidimensionality assumption, we implemented a nonlinear factor analysis procedure. Specifically, we used the method of comparing the ratio of first to second eigenvalues (obtained using an iterated principal-axis factor analysis) for each within-scale matrix of tetrachoric correlations (Lord, 1980). There appeared to be support for the assumption that one dominant dimension is being tapped by the scale's items, as one dimension accounted for a substantial portion of the variance $(34 \%)$.

BILOG (Mislevy \& Bock, 1990) was used to estimate item parameters, as well as participants' latent trait. We fit a 2-Parameter Logistic IRT model to the workplace deviancy items, which involves estimating the discrimination $(a)$ and difficulty (b) parameters. For the most part, the BILOG defaults were used, which means that the method of marginal maximum likelihood was used to estimate the difficulty parameters, and the discrimination parameters were estimated using marginal maximum a posteriori, a Bayesian procedure (see Hambleton, Swaminathan, \& Rogers, 1991). We used the Bayesian procedure of expected a posteriori (see Hambleton et al., 1991) to obtain theta estimates for each participant. In terms of reliability, the Cronbach's alpha for the set of dichotomous items was .60. Examination of the test information function (TIF) showed that the scale provided reliable information for the high end of $\theta$, from 0 to 2.5 on the $\theta$ scale.

Although IRT analyses suggested that internal consistency of the CWB measure is good, this study lacks evidence for testretest reliability or interreporter reliability for the CWB measure. However, it is relevant that the members of this birth cohort have been repeatedly interviewed about delicate private topics such as illegal behavior, drug abuse, sexuality, domestic violence, and suicide attempts, and by age 26 cohort members had learned that they could trust the study team's guarantee of confidentiality. Thus, there is good reason to believe that cohort members' self reports of past-year CWBs were trustworthy.

\section{Results}

The percentages for the items that make up the Counterproductive Work Behavior Index are shown in Table 1. The participation rates varied markedly, with over half of the sample being late to work at least once and $1 \%$ of the sample admitting to stealing money from work.

\section{Correlational Analyses}

The raw correlations between background factors and CWBs also are shown in Table 1. As hypothesized, adolescent conduct disorder was a statistically significant predictor of CWBs in young adulthood $(r=.11, p<.05)$. Our second hypothesis, concerning past official conviction for criminal activity predicting CWBs, was not supported. Adolescent criminal convictions were unrelated to committing counterproductive activities at work. In fact, according to the item-level statistics, people with an adolescent criminal conviction record were less likely to get in a fight with their supervisor or to steal things from work. Also, contradicting our third hypothesis, childhood cognitive ability was positively related to the overall CWB index $(r=.10, p<.05)$. In particular, people who were more intelligent according to childhood measures of cognitive ability were more prone to use equipment at work without permission and to steal money and materials from work (see Table 1). 
Table 1. Percentages of Participants Committing Counterproductive Work Behaviors (CWBs) and Correlations With Background Factors

\begin{tabular}{|c|c|c|c|c|}
\hline Counterproductive act & $\%$ & $\begin{array}{l}\text { Conduct } \\
\text { disorder }\end{array}$ & $\begin{array}{l}\text { Adolescent criminal } \\
\text { convictions }\end{array}$ & $\begin{array}{l}\text { Average cognitive } \\
\text { ability, ages } 7-13\end{array}$ \\
\hline \multicolumn{5}{|l|}{ How many times in the past year ... } \\
\hline have you been late to work? & 51 & .04 & -.02 & .03 \\
\hline $\begin{array}{l}\text { have you pretended you were sick or injured, or gave another false excuse } \\
\text { so you could get time off work? }\end{array}$ & 34 & .04 & .01 & -.01 \\
\hline $\begin{array}{l}\text { have you used things at work without permission (like using the telephone, } \\
\text { Xerox machine, computer, tools or a company car without permission)? }\end{array}$ & 17 & .04 & -.08 & .15 \\
\hline $\begin{array}{l}\text { have you lost your temper, had a fight, or got into an argument with } \\
\text { someone at work? }\end{array}$ & 25 & .15 & .06 & .04 \\
\hline $\begin{array}{l}\text { have you done your job in a way that could cause you to lose it (like taking } \\
\text { shortcuts, missing deadlines, breaking safety rules)? }\end{array}$ & 6 & .14 & .06 & -.02 \\
\hline did you steal money from the place where you worked? & 1 & .03 & -.04 & .09 \\
\hline $\begin{array}{l}\text { did you purposely damage or destroy property, equipment, tools or } \\
\text { merchandise where you work? }\end{array}$ & 1 & .12 & -.01 & -.03 \\
\hline have you been under the influence of alcohol or drugs while you were at work? & 19 & .20 & .08 & .04 \\
\hline Total CWBs & & .11 & -.01 & .10 \\
\hline
\end{tabular}

$\mathrm{Ns}=930$ for criminal activity and 922 for conduct disorder. All correlations shown in boldface are statistically significant at $p<.05$.

Table 2 shows the correlations between CWBs and personality traits assessed at age 18 . Consistent with our hypotheses, traits from the domain of Constraint and Negative Emotionality were statistically significant predictors of CWBs at age 26. The superfactor scale of Negative Emotionality was positively related to CWBs $(r=.21, p<.05)$, as were the subscales of Aggression $(r=.24, p<.05)$, Stress Reaction $(r=.08, p<.05)$, and Alienation $(r=.15, p<.05)$. Conversely, the superordinate factor scale of Constraint was negatively related to CWBs $(r=-$ $.27, p<.05)$ as well as each constituent element of Constraint: Self-Control $(r=-.23, p<.05)$, Harm Avoidance $(r=-.21, p<$ $.05)$, and Traditionalism $(r=-.16, p<.05)$. The Positive Emotionality superfactor scale was unrelated to CWBs, yet specific subscales from the Positive Emotionality domain were statistically significant predictors. Social Closeness was negatively related to CWBs $(r=-.13, p<.05)$, and Social Potency was positively related to CWBs $(r=.14, p<.05)$. Thus, adolescents who were less controlled, more aggressive and alienated, more assertive, and less sociable were more likely to commit counterproductive behaviors as young adults.

Table 2 also shows that the predictive pattern of correlations for the personality traits was quite consistent at the item level of analysis. The personality traits of Self-Control and Aggression had the most consistent pattern of correlates across the CWB items. Self-Control correlated significantly with 9 of the 11 CWB items, and Aggression correlated significantly with 8 of the 11 CWB items. Individuals who were less controlled and more aggressive were more likely to commit the majority of the counterproductive behaviors, with the exception of stealing money from work, which was unrelated to all personality predictors. Of interest, Social Potency had a pattern of positive correlates focused mostly on interpersonal problems, such as having a conflict with a supervisor or having a fight at work.
Table 3 shows the correlations between work conditions at age 26 and the propensity to commit CWBs at age 26. Consistent with our hypotheses, employees who were more satisfied were less likely to participate in CWBs $(r=-.20, p<.05)$. Similarly, individuals afforded more autonomy in their work were also less likely to commit CWBs $(r=-.11, p<.05)$. In contrast, both occupational attainment and resource power had some correlations with the items, but not the overall index of CWB. The lack of overall relationship for occupational attainment with CWBs was the result of a conflicting pattern of positive and negative relationships with CWB items. People in higher status jobs were more likely to use equipment without permission $(r=.10)$ and to steal from work $(r=.07)$ but were less likely to perform acts they felt would result in their being fired $(r=-10)$ or to damage equipment $(r=-10)$. Resource power had only two statistically significant correlates. People with more resource power were more likely to have fights at work $(r=.12)$ and to come to work under the influence of substances $(r=.08)$. The correlation with fighting at work was reasonable because these individuals typically supervised more people and thus had a higher probability of conflict. Work autonomy was much more strongly related to factors such as not being late to work $(r=-.16)$ or pretending to be sick $(r=-.10)$. Thus, people with more autonomy were less likely to malinger and avoid work.

\section{Multiple Regression Analyses}

It is possible that many of these variables are not unique predictors of CWBs. For example, adolescent conduct disorder may account for some of the personality effects, or conversely, personality traits may mediate the relationship of adolescent conduct disorder and adult CWBs. Also, we did not control for other factors that may contribute to CWBs, such as 


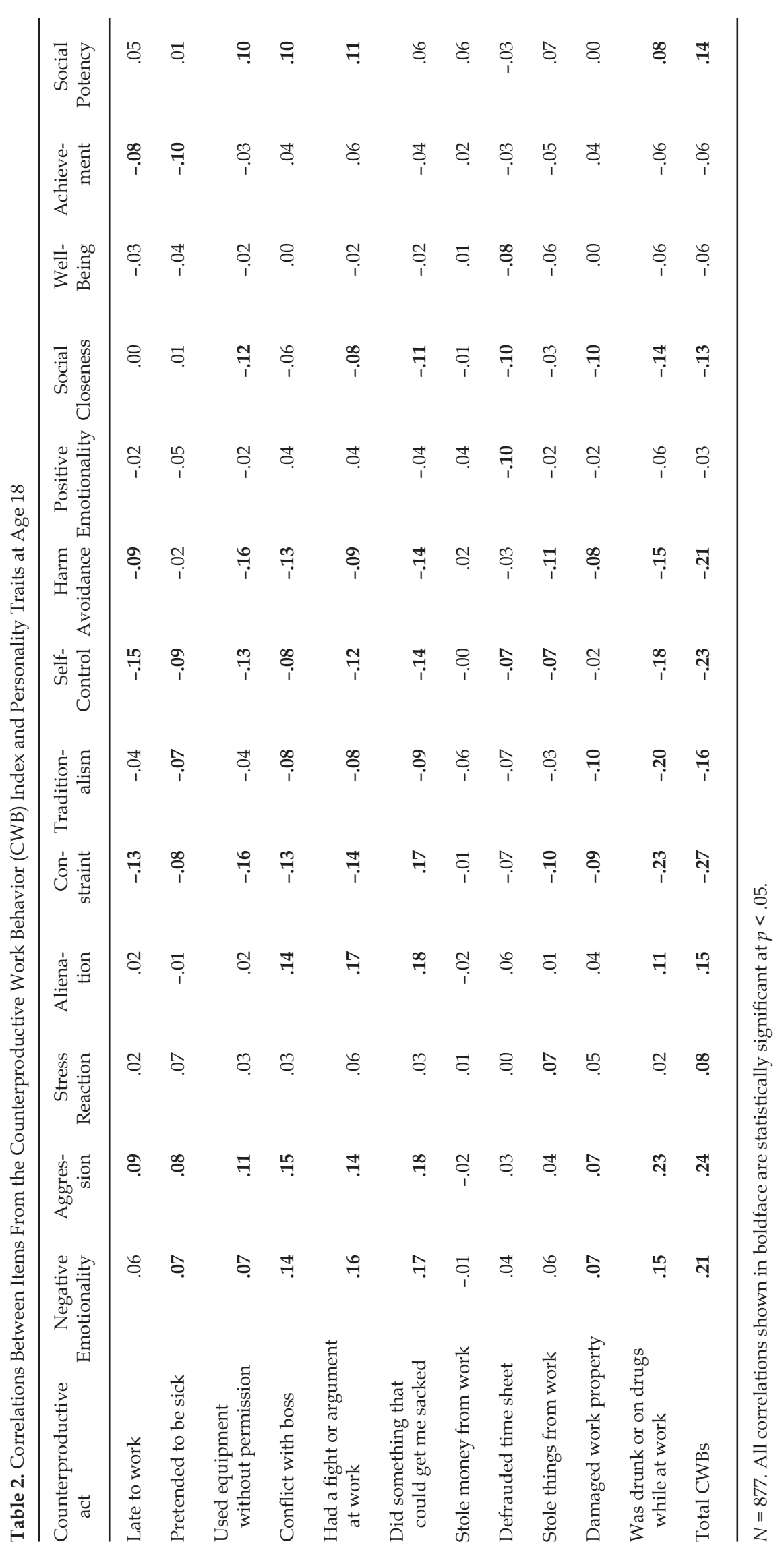


Table 3. Correlations Between Items From the Counterproductive Work Behavior (CWB) Index and Work Conditions at Age 26

\begin{tabular}{|c|c|c|c|c|}
\hline $\begin{array}{l}\text { Counterproductive } \\
\text { act }\end{array}$ & $\begin{array}{r}\text { Cccupational } \\
\text { level }\end{array}$ & $\begin{array}{c}\text { Work } \\
\text { satisfaction }\end{array}$ & $\begin{array}{l}\text { Resource } \\
\text { power au }\end{array}$ & $\begin{array}{l}\text { Work } \\
\text { tonomy }\end{array}$ \\
\hline Late to work & -.03 & -.09 & .03 & -.16 \\
\hline Pretended to be sick & -.03 & -.16 & -.03 & -.10 \\
\hline $\begin{array}{l}\text { Used equipment without } \\
\text { permission }\end{array}$ & at & -.06 & -.03 & -.08 \\
\hline Conflict with boss & -.08 & -.20 & .06 & -.05 \\
\hline $\begin{array}{l}\text { Had a fight or argument } \\
\text { at work }\end{array}$ & -.06 & -.12 & .12 & .04 \\
\hline $\begin{array}{l}\text { Did something that } \\
\text { could get me sacked }\end{array}$ & -.10 & -.08 & .00 & -.06 \\
\hline Stole money from work & -.01 & -.03 & .00 & .00 \\
\hline Defrauded time sheet & .02 & -.06 & -.01 & -.07 \\
\hline Stole things from work & .07 & -.05 & -.01 & -.09 \\
\hline Damaged work property & -.10 & .02 & .00 & -.04 \\
\hline $\begin{array}{l}\text { Was drunk or on drugs } \\
\text { while at work }\end{array}$ & -.07 & -.07 & .08 & .07 \\
\hline Total CWBs & .06 & -.20 & -.04 & -.11 \\
\hline
\end{tabular}

$N=927$. All correlations shown in boldface are statistically significant at $p<.05$.

work satisfaction and autonomy. Thus, we conducted a hierarchical multiple regression to test the independent effects of the background factors, personality traits, and work conditions on CWBs. Table 4 shows the correlations among the variables used in the regression models.

On the first step of the regression, we entered adolescent conduct disorder, criminal convictions that occurred prior to entering the workforce, and childhood cognitive ability. As can be seen in Table 5, both adolescent conduct disorder and childhood cognitive ability were positive predictors of CWBs. Smarter individuals diagnosed with conduct disorder in adolescence were more likely to participate in CWBs in young adulthood. Criminal activities recorded until age 18 were unrelated to CWBs at age 26. On the second step of the regression model, we entered four personality variables. We used the lower order scales exclusively because of the complex re-
Table 5. Situational and Individual-Differences Variables Predicting Counterproductive Work Behaviors

\begin{tabular}{lrrr}
\hline Variable & Step & Step & Step \\
& 1 & 2 & 3 \\
\hline Childhood factors & & & \\
Adolescent conduct disorder & .19 & .09 & .08 \\
Criminal convictions up to age 18 & -.03 & -.08 & -.06 \\
Average IQ, ages 7-13 & .10 & .07 & .08 \\
Age 18 personality & & & \\
Age 18 Self-Control & & -.17 & -.16 \\
Age 18 Aggression & & .14 &. $\mathbf{1 2}$ \\
Age 18 Social Potency & & .05 & .07 \\
$\quad$ Age 18 Social Closeness & & -.09 & -.08 \\
Job characteristics at age 26 & & & \\
Occupational attainment & & & .01 \\
Work satisfaction & & & -.19 \\
Resource power & & &. $\mathbf{1 0}$ \\
Work autonomy & & & -.10 \\
$R$ & .20 &. $\mathbf{3 1}$ & \\
\hline
\end{tabular}

Note. $N=838$. Standardized beta weights and Rs shown in boldface are statistically significant at $p<.05$.

lationship of the Positive Emotionality scales with CWBs (i.e., the negative relationship of Social Closeness and the positive relationship of Social Potency cancelled each other out at the superfactor level). We also selected only one scale from each domain of the MPQ, with the exception of Positive Emotionality, in order to avoid problems with multicollinearity. We selected the Self-Control scale from the Constraint domain, the Aggression scale from the Negative Emotionality domain, and the Social Closeness and Social Potency scales from the Positive Emotionality domain, based on their correlations with CWBs.

When we controlled for conduct disorder, prior criminal convictions, and childhood cognitive ability, three of the four personality scales remained statistically significant predictors of CWBs (Self-Control, Social Closeness, and Aggression). The inclusion of the personality variables resulted in a marked

Table 4. Intercorrelations Between Regression Variables

\begin{tabular}{|c|c|c|c|c|c|c|c|c|c|c|c|c|}
\hline Variable & 1 & 2 & 3 & 4 & 5 & 6 & 7 & 8 & 9 & 10 & 11 & 12 \\
\hline 2. Adolescent conduct disorder & -.12 & .83 & & & & & & & & & & \\
\hline 4. Age 18 Self-Control & -.05 & -.21 & -.16 & .79 & & & & & & & & \\
\hline 5. Age 18 Aggression & .07 & .36 & .19 & -.37 & .78 & & & & & & & \\
\hline 8. Occupational level & .44 & -.25 & -.15 & .15 & -.21 & .20 & .10 & .75 & & & & \\
\hline 9. Work satisfaction & .04 & -.09 & -.02 & .09 & -.12 & .04 & .12 & .20 & .63 & & & \\
\hline 10. Resource power & .06 & .08 & .02 & .01 & .02 & .11 & -.01 & .11 & .13 & .67 & & \\
\hline 11. Work autonomy & .10 & .04 & .11 & .02 & .00 & .10 & -.02 & .15 & .14 & .32 & .69 & \\
\hline 12. CWBs & .08 & .17 & .01 & -.25 & .25 & .14 & -.15 & -.07 & -.23 & .06 & -.09 & .60 \\
\hline
\end{tabular}

$N=838$. All correlations shown in boldface are statistically significant at $p>.05$. Internal consistency reliabilities are shown on the diagonal. $\mathrm{CWB}=$ counterproductive work behavior. 
drop in the magnitude of the effect of adolescent conduct disorder on CWBs. In fact, according to the Sobel's $z$ test (Kenny, Kashy, \& Bolger, 1998; Sobel, 1982) the Social Closeness, Aggression, and Self-Control scales were significant mediators of the relationship between conduct disorder and CWBs. Of the three scales, Aggression was the strongest mediator $(z=5.2, p$ $<.05)$, which fits well the emphasis on "hostility" in the prior literature on CWBs. (It should be noted that the MPQ Aggression scale does not share item content overlap with conduct disorder; the conduct disorder scale assesses actual behaviors committed, such as fighting or stealing, whereas the Aggression scale assesses attitudes and interests, such as enjoyment of violent films.)

In the third step of the regression equation, we entered the four work variables. Consistent with much previous research, work satisfaction was negatively related to CWBs $(\beta=-.19, p$ $<.05)$, indicating that workers who are dissatisfied with their work are more likely to participate in counterproductive behaviors. Likewise, work autonomy was negatively related to CWBs $(\beta=-.10, p<.05)$. In contrast, resource power was positively related to CWBs $(\beta=.10, p<.05)$, indicating that employees with more control over resources were more likely to commit CWBs. The inclusion of the work variables did not substantially affect any of the previous predictors. Of interest, the magnitude of the effects of personality traits was similar to the magnitude of the work context variables, despite the fact that the work context factors were assessed concurrently with the CWBs, whereas personality had been assessed 8 years earlier.

\section{Discussion}

The present study tested the relations between a battery of background factors and CWBs in an ongoing longitudinal study of young adults. In contrast to much of the previous research, the design of the present study was unique, in that the background information was gathered concurrently as the participants' lives unfolded, rather than retrospectively. The results showed that individuals diagnosed with childhood and adolescent conduct disorder were more prone to commit CWBs in young adulthood and that these associations were partially mediated by personality traits measured at age 18. Job conditions and evaluations had independent effects on CWBs above and beyond personality traits. We discuss each of these patterns and their implications in turn.

The present study confirmed that a suite of background factors can be used to predict CWBs in young adulthood. Adolescent conduct disorder proved to be the best predictor in the first stage of the regression model. This pattern of predictors seems reasonable if CWBs are viewed from a theoretical standpoint as work-context-specific features of a wider tendency toward antisocial behavior across contexts. Conduct disorder appearing in childhood and adolescence is the earliest emerging feature of this wider antisocial tendency in the life course, and it is known to predict a variety of antisocial activities in adulthood (Moffitt et al., 2001).

Of most interest was the fact that childhood conduct disorder was associated with CWBs measured in young adulthood. This indicates that there are important continuities from childhood to adulthood in people's lives that can have serious ramifications for their well-being and occupational success. This is not to say that childhood character is fate, as the effect of childhood conduct disorder was small in magnitude. Moreover, early childhood conduct disorder most likely results in both personality and environmental issues that form a cocktail of factors that may independently contribute to poor outcomes in adulthood. For example, conduct disorder may contribute to an impulsive adult personality but might also contribute to poor educational outcomes, which may have independent, negative effects on work outcomes (Moffitt et al., 2001). The continuity in psychological factors from childhood to adulthood also indicates that early interventions to ameliorate conduct disorder problems would have significant, positive life course consequences for individuals.

In contrast to the effect of adolescent conduct disorder, adolescent criminal convictions did not predict CWBs in young adulthood. Given the similarity between the two constructs of conviction and CWBs, one would expect that past violent convictions, for example, would be related to aggressive behaviors at work. In fact, criminal conviction actually had small negative relationships with fighting or stealing at work. One potential explanation is that being caught and convicted for criminal activities acted as a preventative buffer against future CWBs; these individuals learned their lesson. Another interpretation is that the fear of losing one's job is greater for those with a criminal conviction background, which leads these people to be more careful on the job to avoid getting fired. A third possibility arises from the established fact that conviction is an imperfect indicator of true illicit behaviors, and most crimes go undetected. This could imply that individuals who engage in illicit behavior but are clever enough to evade detection and conviction are also able to negotiate entry into jobs, whereas in contrast, unfortunate individuals who are frequently convicted for their crimes experience less time employed, and as a result have fewer opportunities to engage in CWBs. This finding is important, as there is little or no predictive validity data on the relationship between past criminal behavior and counterproductive behaviors at work. Our findings point to the necessity of examining these patterns more closely, as many organizations screen potential employees for past criminal behavior under the assumption that they are eliminating potential problem employees, which may not be the case. ${ }^{1}$ The present study constituted a rigorous test of the ability of conviction records to predict CWBs when both data sources are uncontaminated by each other, because conviction data were systematically obtained by a background-check search of police computer records whereas CWBs were measured separately in interviews carried out under conditions of strict confidentiality that fostered frank reporting.

Unlike past criminal convictions, childhood cognitive ability had a positive relationship with CWBs. Specifically, participants with higher cognitive ability scores in childhood were more likely to use equipment for personal uses and steal from the organization. One interpretation of these findings is that high-IQ individuals have a stronger sense of entitlement, and therefore feel justified in using equipment and taking resources from an organization. The finding was surprising given the previous research showing a negative relationship between cognitive ability and CWBs (Dilchert et al., 2007; Duehr et al., 2006). One reason for the discrepancy may lie in

\footnotetext{
${ }^{1}$ It should be noted that organizations cannot use adolescent criminal records when screening potential employees and that investigations of adult criminal activity may show a different pattern of relations to CWBs.
} 
the samples typically studied in organizational studies. Many organizational studies use samples of relatively high-functioning individuals who are either college students or members of a single organization. Cognitive ability within a single organization may play a different role than cognitive ability across organizations, like those examined in the Dunedin study. For example, within organizations, it may be clear to employees that theft is a problem, and therefore employees with higher cognitive ability may avoid stealing materials from work more than employees with lower cognitive ability. Across organizations, however, other mechanisms and processes may drive a different relationship between cognitive ability and CWBs. For example, people with higher cognitive ability may pursue and get selected into jobs that have more resources to steal. In contrast, people with low cognitive ability may end up disproportionately in jobs that afford fewer resources to steal (e.g., sheep shearer, slaughterer). Thus, the positive association between cognitive ability and theft may have occurred because higher cognitive ability leads to jobs that afford greater opportunity to steal, relative to low-ability jobs.

Despite controlling for these background factors, we found that personality traits assessed at age 18 had consistent predictive relations to CWBs assessed at age 26. Moreover, personality traits mediated the effect of childhood conduct disorder on CWBs. Consistent with a wide variety of research from clinical and industrial psychology, the two most important personality trait domains were from the domains of Agreeableness and Conscientiousness (Berry et al., 2007). The Aggression and Social Closeness scales were some of the strongest predictors of total CWBs. Also, all four scales tapping the domain of Constraint, which is strongly related to Conscientiousness, predicted CWBs as well. Thus, people with a strong compulsion to adhere to norms, control their impulses, and avoid hostility tend not to commit counterproductive activities at work. In addition, individuals who scored higher on Social Potency tended to commit more CWBs, largely because they were involved in more interpersonal conflicts. The fact that personality traits mediated the effect of conduct disorder on CWBs bodes well for the use of personality tests as selection tools. Personality tests appear to serve as a proxy for background factors, such as childhood and adolescent conduct disorder, which most organizations cannot assess reliably or validly. However, some caution is warranted in making inferences from our findings to real personnel recruitment situations, because individuals seeking a job may be motivated to attempt to portray their personalities in a positive light, whereas such motivation probably did not strongly bias the cohort members' self-reports of personality in our research setting.

Individual differences in personality and other background factors are only part of the story behind CWB. Much research has pointed to the importance of the work context and job attitudes as antecedents of counterproductive activities (e.g., Robinson \& O'Leary-Kelly, 1998). Consistent with this research, we found that people in more satisfying, autonomous jobs engaged in fewer counterproductive behaviors, whereas people with more resource power tended to engage in more-although it should be noted that the latter was most likely the result of experiencing more interpersonal conflict, which would be a natural consequence of supervising more people.

Despite the multiple methods and relatively long-term prospective design of the study, the present study also has important limitations. Most conspicuously, the findings may not be directly relevant to selection, as the sample studied was quite heterogeneous in the number and type of jobs occupied. As we noted in our discussion of the counterintuitive findings for childhood cognitive ability, this heterogeneity may result in a qualitatively different pattern of results compared with that of more prototypical validation studies. On the other hand, the fact that personality traits and job conditions found to be important in narrower samples replicated in the Dunedin study bolsters the generalizability of these findings.

A second limitation was that we focused only on young adults and therefore have little or no information concerning whether these patterns hold for older individuals. It is quite possible that the patterns will change with age, with different personality traits and job conditions becoming more important for older workers. Third, we used a measure of counterproductive behaviors created specifically for this study. In contrast to existing measures of CWBs, this measure emphasized serious transgressions, such as stealing and physical violence, rather than less extreme attitudinal features of CWBs, such as withholding effort or work withdrawal. Limiting the construct to more serious offenses most likely limited our ability to predict these CWBs, as they occur at a lower base rate than behaviors reflecting a disaffected attitude. Also, our measure was not designed to differentiate between the two facets of CWBs - interpersonal and organizational deviance (Robinson \& Bennett, 1995) - which though highly correlated (Dalal, 2005) can have slightly different correlates with personality variables (Berry et al., 2007). In terms of our predictor measures, the internal consistency reliability varied somewhat from measure to measure. This could, within the present study, undermine the comparability of the magnitude of the validity coefficients. Of course, a true comparison of the magnitude of the relative effect sizes of personality and organizational variables is best made when based on meta-analytic data. Finally, although the predictors were gathered using observer, interview, and self-report techniques, the majority of variables were assessed via self-report. Future research should incorporate observer ratings of personality and job behaviors in order to test whether these background factors generalize across methods.

Future research could identify and examine potential mediators of the relationship between personality and CWBs or other voluntary work behaviors. Like job performance, specific types of goals may mediate this relationship (e.g., Barrick, Stewart, \& Piotrowski, 2002). For example, people who are more conscientious may also have more prosocial goals. In the work context, this would manifest itself as a propensity not to engage in CWBs. Another possibility for future research would be to examine the effect of type of industry or type of vocation (Holland, 1985) on the predictors of CWBs. For example, in Holland's system, jobs are organized into six broad psychological categories (i.e., Realistic, Investigative, Artistic, Social, Enterprising, and Conventional). The antecedents to CWBs may be different in Artistic jobs (e.g., artist, architect) than in Social jobs (e.g., administrative assistant, nurse). Moreover, these different types of jobs may afford different forms of CWBs, such that certain jobs engender greater interpersonal rather than organizational deviance. Of course, a study examining these factors would by necessity have to be quite large. 
In summary, CWBs appear to be predictable from childhood and adolescent activities. Furthermore, the links between childhood and adolescent conduct disorder and CWBs were accounted for by personality traits associated with Agreeableness and Conscientiousness. Finally, work conditions were also important, independent predictors of CWBs, alluding to the fact that an interactionist model of CWBs may be the most productive representation of the phenomenon.

\section{References}

American Psychiatric Association (1994). Diagnostic and statistical manual of mental disorders (4th ed.). Washington, DC: Author.

Barrick, M. R., Stewart, G. L., \& Piotrowski, M. (2002). Personality and job performance: Test of the mediating effects of motivation among sales representatives. Journal of Applied Psychology, 87, 43-51.

Berry, C. M., Ones, D. S., \& Sackett, P. R. (2007). Interpersonal deviance, organizational deviance, and their common correlates. Journal of Applied Psychology, 92, 410-424.

Colbert, A. E., Mount, M. K., Harter, J. K., Witt, L. A., \& Barrick, M. R. (2004). Interactive effects of personality and perceptions of the work situation on workplace deviance. Journal of Applied Psychology, 89, 599-609.

Connerley, M. L., Arvey, R. D., \& Bernardy, C. J. (2001). Criminal background checks for prospective and current employees: Current practices among municipal agencies. Public Personnel Management, 30, 173-183.

Dalal, R. S. (2005). A meta-analysis of the relationship between organizational citizenship behavior and counterproductive work behavior. Journal of Applied Psychology, 90, 1241-1255.

Dilchert, S., Ones, D. S., Davis, R. D., \& Rostow, C. D. (2007). Cognitive ability predicts objectively measured counterproductive workplace behaviors. Journal of Applied Psychology, 92, 616-627.

Duehr, E. E., Sackett, P. R., \& Ones, D. S. (2006). A facet-level examination of the relationship between integrity and cognitive ability. Unpublished manuscript, University of Minnesota.

Greenberger, E., \& O'Neil, R. (1993). Spouse, parent, worker: Role commitments and role-related experiences in the construction of adults' well being. Developmental Psychology, 29, 181-197.

Hambleton, R. K., Swaminathan, H., \& Rogers, H. J. (1991). Fundamentals of item response theory. Newbury Park, CA: Sage.

Henry, B., Moffitt, T. E., Caspi, A., Langley, J., \& Silva, P. A. (1994). On the "remembrance of things past": A longitudinal evaluation of the retrospective method. Psychological Assessment, 6, 92-101.

Holland, J. L. (1985). Making vocational choices: A theory of careers. Englewood Cliffs, NJ: Prentice Hall.

Hollinger, R. C., \& Clark, J. P. (1983). Deterrence in the workplace: Perceived certainty, perceived severity, and employee theft. Social Forces, 62, 398-418.

Kenny, D. A., Kashy, D. A., \& Bolger, N. (1998). Data analysis in social psychology. In D. T.Gilbert, S. T.Fiske, \& G.Lindzey (Eds.), The handbook of social psychology (pp. 233-265). Boston: McGraw-Hill.

Krueger, R. F., Caspi, A., \& Moffitt, T. E. (2000). Epidemiological personology: The unifying role of personality in population-based research on problem behaviors. Journal of Personality, 68, 967-998.

Lau, V. C. S., Au, W. T., \& Ho, J. M. C. (2003). A qualitative and quantitative review of antecedents of counterproductive behavior in organizations. Journal of Business and Psychology, 18, 73-99.

Lee, K., \& Allen, N. J. (2002). Organizational citizenship behavior and workplace deviance: The role of affect and cognitions. Journal of Applied Psychology, 87, 131-142.
Lee, K., Ashton, M. C., \& Shin, K. H. (2005). Personality correlates of workplace anti-social behavior. Applied Psychology: An International Review, 54, 81-98.

LePine, J. A., \& Van Dyne, L. (2001). Voice and cooperative behavior as contrasting forms of contextual performance: Evidence of differential relationships with Big Five personality characteristics and cognitive ability. Journal of Applied Psychology, 86, 326-336.

Lord, F. M. (1980). Applications of item response theory to practical testing problems. Hillsdale, NJ: Erlbaum.

Meyer, G. J., Finn, S. E., Eyde, L. D., Kay, G. G., Moreland, K. L., Dies, R. R., et al. (2001). Psychological testing and psychological assessment. American Psychologist, 56, 128-165.

Mislevy, R. J., \& Bock, R. D. (1990). BILOG 3 Item Analysis and Test Scoring With Binary Logistic Models[Computer program]. Mooresville, IN: Scientific Software.

Moffitt, T. E., Caspi, A., Rutter, M., \& Silva, P. A. (2001). Sex differences in antisocial behavior: Conduct disorder, delinquency, and violence in the Dunedin longitudinal study. Cambridge, England: Cambridge University Press.

Ones, D. S. (2002). Introduction to the special issue on counterproductive behaviors at work. International Journal of Selection and Assessment, 10, 1-4.

Ones, D. S., \& Viswesvaran, C. (2001). Personality at work: Criterionfocused occupational personality scales used in personnel selection. In B. W.Roberts \& R.Hogan (Eds.), Personality psychology in the workplace (pp. 63-92). Washington, DC: American Psychological Association.

Ones, D. S., \& Viswesvaran, C. (2003). Personality and counterproductive behaviors. In A.Sagie, S.Stashevsky, \& M.Koslowsky (Eds.), Misbehavior and dysfunctional attitudes in organizations (pp. 211249). Houndmills, Hampshire, England: Palgrave Macmillan.

Ones, D. S., Viswesvaran, C., \& Schmidt, F. L. (1993). Comprehensive meta-analysis of integrity test validities: Findings and implications for personnel selection and theories of job performance. Journal of Applied Psychology, 78, 679-703.

Roberts, B. W., Caspi, A., \& Moffitt, T. E. (2003). Work experiences and personality development in young adulthood. Journal of Personality and Social Psychology, 84, 582-593.

Roberts, B. W., Chernyshenko, O., Stark, S., \& Goldberg, L. (2005). The structure of Conscientiousness: An empirical investigation based on seven major personality questionnaires. Personnel Psychology, $58,103-139$.

Robinson, S. L., \& Bennett, R. J. (1995). A typology of deviant workplace behaviors: A multidimensional scaling study. Academy of Management Journal, 38, 555-572.

Robinson, S. L., \& O'Leary-Kelly, A. M. (1998). Monkey see, monkey do: The influence of work groups on the antisocial behavior of employees. Academy of Management, 41, 658-672.

Sackett, P. R., \& DeVore, C. J. (2001). Counterproductive behaviors at work. In N.Anderson, D. S.Ones, H.Sinangil, \& C.Viswesvaran (Eds.), Handbook of industrial, work, and organizational psychology (Vol. 1). London: Sage.

Salgado, J. (2002). The Big Five personality dimensions and counterproductive behaviors. International Journal of Selection and Assessment, 10, 117-125.

Silva, P. A., \& Stanton, W. (Eds.). (1996). From child to adult: The Dunedin study. Auckland, New Zealand: Oxford University Press.

Sobel, M. E. (1982). Asymptotic confidence intervals for indirect effects in structural equation models. In S.Leinhardt (Ed.), Sociological methodology 1982 (pp. 290-312). Washington, DC: American Sociological Association.

Tellegen, A. (1982). Brief manual of the Multidimensional Personality Questionnaire. Unpublished manuscript. University of Minnesota.

Wechsler, D. (1974). Manual for the Wechsler Intelligence Scale for Children-Revised. New York: Psychological Corporation. 